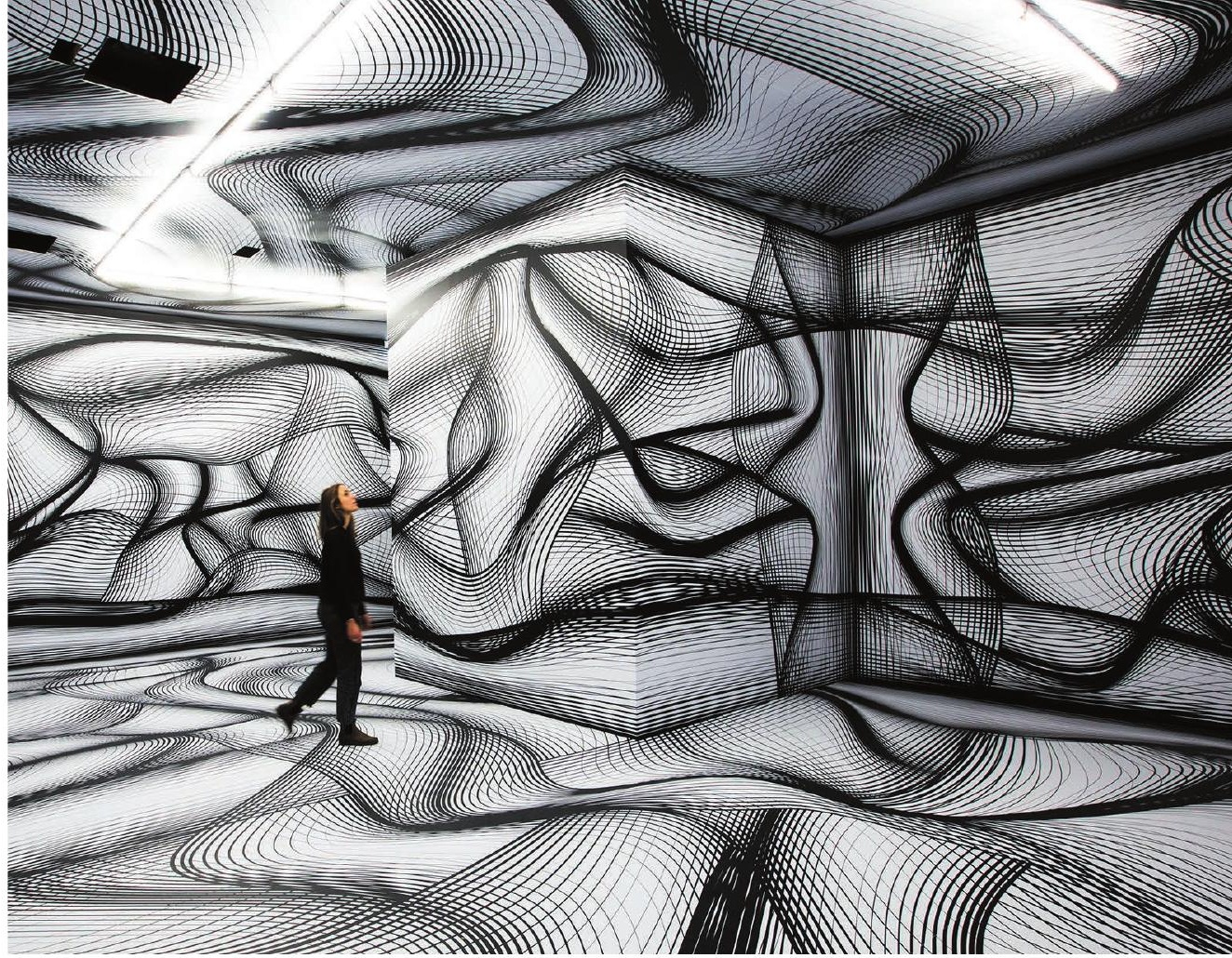

Untitled 2018, one of Peter Kogler's installations of computer-assisted art.
By acknowledging the ambiguous way in which genes actually work, and by embracing all these other factors that shape our lives, we make CRISPR less threatening because it is less definitive.

Zimmer deconstructs the idea of the body as a genetic temple, built on Mendel's sacrosanct 'laws', along with genetic determinism. Instead, he calls for a view that includes "culture, epigenetic marks, hitchhiking microbes, or channels we don't even know about yet". His argument is balanced and fair, comprehensive and bang up to date. Whatever your views on the power of genes versus other forms of heredity, you will be in for a few surprises.

There are some weaknesses. Zimmer makes no real attempt to explain how Mendel's laws arose in our single-celled ancestors, and offers rather cursory descriptions of early evolution. And his sympathy for the underdog can go too far. His portrait of crystallographer Rosalind Franklin, for example, seemed to me too partial. You would never imagine, from Zimmer's depiction of her meticulous science, that Franklin had circulated an obituary of the DNA helix nine months before Francis Crick and James Watson's paper on the double helix appeared in Nature. But these are quibbles.

In She Has Her Mother's Laugh, Zimmer has built a subtle, multifaceted and deep understanding of heredity, grounded in revelatory insights from genome sequencing. And he shows that we will need it to face our uncertain future.

Nick Lane is professor of evolutionary biochemistry at University College London, and author of four books on evolution, most recently The Vital Question: Why is Life the Way it Is? e-mail:nick.lane@ucl.ac.uk

\title{
Can robots make art?
}

\section{Laura Spinney encounters a Paris exhibition that probes the concept of algorithmic creativity.}

$\mathrm{V}$ isiting the exhibition Artists and Robots at the Grand Palais in Paris, I happened on the artist ORLAN, best known for her work involving body modification. She was standing close to her 2017 work ORLAN and the ORLANOID, in which her video presence interrogates a lookalike robot on matters of life and death. Having borrowed the robot's lensless glasses for a photo shoot, she needed her own back. I was struck by the robot's lack of reaction as she made the swap. It underscored my answer to the question posed by this exhibition: can a robot create a work of visual art?

My feeling is no, for the simple reason that it can't see. I recommend the show, nonetheless. It forced me to examine what I mean by seeing or - more broadly - sensing

the world, and hence what I mean by art.

Artists and Robots showcases robots and their output in roughly chronological sections. The first recounts how, starting in the 1950s, visionary artists such as Jean Tinguely and Nicolas Schöffer built robots - to begin with, no more than collections of mobile parts driven by motors - to create kinetic art. The second tracks that impulse forward from the digital revolution, starting in the 1970s.
Artists and Robots Grand Palais, Paris. Until 9 July 2018.

And the third - optimistically entitled 'The robot emancipates itself' - explores their present status and looks to the future.

When robots were all jointed arms and motors, they executed an artist's vision channelled by their own capacities as machines. Modern French artist Patrick Tresset's ironic spin on this relationship features in the first section of the show. In the installation Human Study \#2, three sets of robot arms and cameras - the 'hand' and 'eye' - repeatedly draw a set of objects including a stuffed fox and a human skull. They are programmed to copy both the objects and Tresset's drawing technique, while introducing small variations that he characterizes as artistic, expressive and obsessional. It's through such serendipitous additions and mistakes, the artist seems to suggest, that the greats became great.

The digital revolution ushered in software and algorithms as artists' tools or assistants, and the possibilities exploded. We see this in stunning works in the second section, from conceptual artist Joan Fontcuberta's selfdescribed "hallucinatory" landscapes to labyrinthine wallpaper from multimedia whizz Peter Kogler. This covers an entire room, so that we seem enclosed in an optical illusion. For me, the works' technical sophistication seems only to accentuate their soullessness, 
and never more so than when they show up the fallibility of human perception.

In 2003-04 paintings from his Orogenesis series, for example, Fontcuberta takes algorithms that create $3 \mathrm{D}$ landscapes from $2 \mathrm{D}$ map coordinates, and forces them to re-interpret the landscape paintings of artists such as J. M. W. Turner and Paul Cézanne. The results are highly naturalistic, but they reminded me of Swiss writer Charles-Ferdinand Ramuz's idea that once the human element is banished from a place, it becomes a non-place.

Likewise Michael Hansmeyer's 2017 Astana Columns. These architectural forms, created by an algorithm that applies evolutionary principles to repeatedly subdivide a Doric column, were assembled from lasercut cardboard and other materials. They provoke awe through their sheer complexity, but in the way that a termite mound does: what's impressive is not that they were imagined, but that they were unimagined.

By the time I reached the future-facing section, where I bumped into ORLAN, I had concluded that, notwithstanding the section's title, the robot had not emancipated itself. Pascal Haudressy's 2009 animation Brain, for example, evolves thanks to glitches the artist introduced into the governing algorithm, that force the computer to continuously recalculate the coordinates of each pixel. Ultimately, however, it is less impressive than animations of the actual evolution of the human brain.

Although artificial intelligence has advanced in leaps and bounds since the 1950 s, artificial imagination has yet to get off the starting blocks. As curators Laurence Bertrand Dorléac and Jérôme Neutres suggest in an explanatory video, these are artists' robots rather than robot artists. But if Artists and Robots doesn't tell you what art is, it does venture into fascinating new territory to tell you what it's not: random copying errors might be necessary, but they are also insufficient.

That said, perhaps robot imaginations have already liberated themselves outside the confines of human artists' studios, and their art is radically different from ours; so different that we don't recognize it when we see it, glasses or no glasses. I can't wait for the first exhibition curated by robots - assuming it's advertised to non-robots.

Laura Spinney is a writer and science journalist based in Paris. e-mail:lfspinney@gmail.com

\section{CORRECTION}

In the article 'Feynman at 100' (Nature 557, 164-165; 2018), a picture caption mistakenly referred to Richard Feynman lecturing at the California Institute of Technology; the picture was actually taken at California State University, Long Beach.

\section{Books in brief}

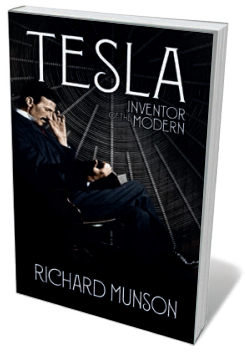

\section{Tesla: Inventor of the Modern}

Richard Munson W. W. NORTON (2018)

Around the turn of the twentieth century, Serbian-born visionary Nikola Tesla authored transformative inventions from the alternatingcurrent system to remote control, drones and (arguably) radio. He even foresaw radar, mobile phones and the Internet. Yet, as Richard Munson reveals in this penetrating biography, Tesla's lack of business sense allowed others to prevail. Munson makes vivid the genius's eventful life, from his mother's inspirational labour-saving inventions to his psychological complexity — and his estimable belief that "technology should transcend the marketplace".

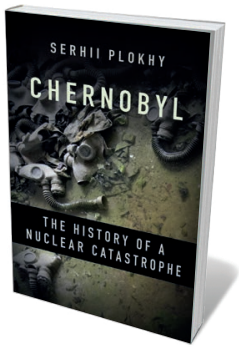

\section{Chernobyl: The History of a Nuclear Catastrophe} Serhii Plokhy BASIC (2018)

Soon after midnight on 26 April 1986, a turbine test at Ukraine's Chernobyl nuclear power plant went stupendously wrong. The explosion released 14 exabecquerels of radiation; the fallout contaminated $20 \%$ of neighbouring Belarus and crossed more than half of Europe. Historian Serhii Plokhy's deft, richly detailed account draws on newly opened archives and weaves in stories of players such as Chernobyl director Viktor Briukhanov. The disaster's roots, he asserts, were a toxic tangle of shoddy construction, human error, flawed governance and complacency in the Soviet nuclear industry.

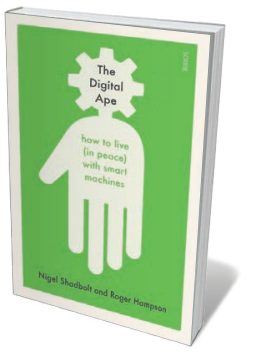

\section{The Digital Ape}

Nige/ Shadbolt and Roger Hampson SCRIBE (2018)

Numbed by dire warnings of technological Armageddon? Computer scientist Nigel Shadbolt and economist Roger Hampson dispel the miasma with this superb survey of the landscape we "digital apes" have wrought. Humanity's tool use, spanning everything from handaxes to CRISPR, has spawned marvels such as a hyper-networked society, "social machines" like Wikipedia and artificial intelligence. But to avoid succumbing to the inherent dangers, Shadbolt and Hampson urge wise choices: to hold Silicon Valley to account, ensure transparent algorithmic decision-making and own our own data.

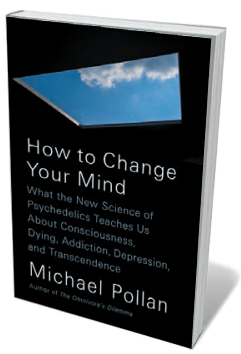

\section{How to Change Your Mind}

Michael Pollan PenGuIn PRESS (2018)

Journalist Michael Pollan explored psychoactive plants in The Botany of Desire (2001). In this bold, intriguing study, he delves further, homing in on psychedelic compounds currently under study, such as psilocybin. He meets a vast cast of researchers, including mycologist Paul Stamets and neuroscientist Robin Carhart-Harris, who works on neural correlates of the psychedelic experience. Pollan even "shakes the snow globe" himself, chemically self-experimenting in the spirit of psychologist William James, who speculated about the wilder shores of consciousness more than a century ago.

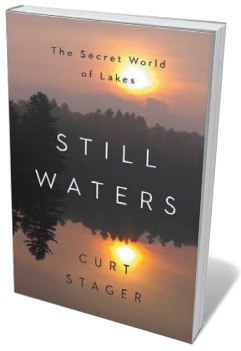

\section{Still Waters}

Curt Stager W. W. NORTON (2018)

"There is nothing like a lake to reflect and reveal the world." So declares ecologist Curt Stager, whose lyrical evocation of 'living waters' offers geological and biological revelations. He also probes our relationship to lakes as one body of water to another, examining mud cores from Walden Pond in Massachusetts (immortalized by nineteenth-century naturalist Henry David Thoreau), flesh-dissolving alkaline minerals in Tanzania's Lake Natron, and the endemic species crowding crystal-clear Lake Baikal in Siberia. Barbara Kiser 